\title{
INSTANTE DE VER, TEMPO PARA COMPREENDER E MOMENTO DE CONCLUIR: APONTAMENTOS SOBRE PSICANÁLISE E EDUCAÇÃO EM CIÊNCIAS'
}

\author{
Wilson Elmer Nascimento ${ }^{1}$ \\ Alberto Villani $^{2}$ \\ https://orcid.org/0000-0002-9802-3192 \\ https://orcid.org/0000-0003-2760-240X
}

\section{RESUMO:}

No presente artigo, buscamos estabelecer uma interlocução com o trabalho de Gleici Kelly de Lima e Rodolfo Langhi, intitulado "Observando o invisível: a relação transferencial a partir dos discursos entre crianças e professoras monitoras em um observatório astronômico”. Considerando que uma das contribuições mais potentes do trabalho é a operacionalização de conceitos psicanalíticos na relação entre educadoras e crianças, direcionamos nosso diálogo às relações entre Psicanálise e Ensino de Ciências. Para isso, dividimos o texto em três seções: na primeira, retomamos algumas reflexões sobre a exploração de analogias entre Psicanálise e Educação em Ciências; posteriormente, aprofundamos a discussão sobre a relação analógica entre os quatro discursos de Lacan e os discursos do professor de Ciências; por fim, enfatizando o papel dos discursos nas diferentes etapas da aprendizagem em ciências, adentramos nas interpretações dos discursos na relação transferencial entre as monitoras e as crianças no observatório astronômico.

\section{EL INSTANTE DE VER, EL TIEMPO DE COMPRENDER Y EL MOMENTO DE CONCLUIR: NOTAS SOBRE PSICOANÁLISIS Y EDUCACIÓN CIENTÍFICA}

\section{RESUMEN:}

En este artículo buscamos dialogar con el trabajo de Gleici Kelly de Lima y Rodolfo Langhi, titulado "Observando lo invisible: la relación transferencial a partir de los discursos entre niños y maestras monitoras en un observatorio astronómico”. Considerando que uno de los aportes más potentes del trabajo es la operacionalización de conceptos psicoanalíticos en la relación entre educadoras y niños, dirigimos nuestro diálogo a la relación entre Psicoanálisis y Educación en Ciencias. Para ello, dividimos el texto en tres secciones: en la primera, retomamos algunas reflexiones sobre la exploración de analogías entre Psicoanálisis y Educación Científica; posteriormente, profundizamos la discusión sobre la relación analógica entre los cuatro discursos de Lacan y los discursos del profesor de Ciencias; finalmente, enfatizando el papel de los discursos en las diferentes etapas del aprendizaje de las Ciencias, nos adentramos en las interpretaciones de los discursos en la relación transferencial entre monitoras y niños en el observatorio astronómico.

\footnotetext{
1 Universidade Federal do Rio Grande do Norte, Centro de Educação, Natal, RN, Brasil.

2 Universidade de São Paulo, Instituto de Física, São Paulo, SP, Brasil.
}

Palavra-chave:

Educação e Psicanálise;

Discursos; Lacan;

Educação em Ciências.

Palabras clave:

Educación y Psicoanálisis;

Discursos; Lacan;

Educación en Ciencias. 


\title{
SEEING MOMENT, COMPREHENSION TIME AND CONCLUDING MO- MENT: NOTES ON PSYCHOANALYSIS AND SCIENCE EDUCATION
}

\begin{abstract}
:
In the present manuscript, we seek to establish a dialogue with the work from Gleici Kelly de Lima and Rodolfo Lanchi, entitled "Observing the invisible: the transference relationship from the discourses between children and monitor teachers in an astronomical observatory." Considering that one of the greatest contributions of the work is the operationalization of psychoanalytic concepts in the relationship between educators and children, we focus our dialogue to the relationship between Psychoanalysis and Science Teaching. In order to do so, we have divided the text into three sections: in the first, we review some thoughts about the exploration of analogies between Psychoanalysis and Science Education; then, we deepen the discussion about the analogic relation between the four Lacan discourses and the Science teacher ones; Lastly, we emphasize the role of the discourses in different learning stages in Science, we cover the interpretations of the speeches in the transference relationship between the monitors and the children in the astronomical observatory.
\end{abstract}

Keywords:

Education and

Psychoanalysis;

Discourses; Lacan;

Science Education.

\section{“CONVERSAS” PRELIMINARES}

"Não bá entrada possivel em análise, sem entrevistas preliminares" (Lacan, 1997, p. 27).

Neste manuscrito buscamos alcançar uma interlocução com o artigo de Gleici Kelly de Lima e Rodolfo Langhi, intitulado Observando o invisivel: a relação transferencial a partir dos discursos entre crianças e professoras monitoras em um observatório astronômico, recentemente publicado na Ensaio Pesquisa em Educação em Ciências. O artigo apresenta os resultados de uma investigação que teve como foco a interpretação dos discursos e as relaçóes de transferência entre crianças e monitoras no contexto de um observatório astronômico. O trabalho trata de temáticas de extrema importância para a área de Ensino de Ciências, sobretudo no que se refere a especial atenção à educação em astronomia para crianças em contextos de educação não-formal, tema relativamente pouco trabalhado em pesquisas acadêmicas. Além disso, lança mão de um referencial teórico bastante original e promissor para as análises de relaçôes entre educadores e educandos, nomeadamente, a psicanálise lacaniana (Lima \& Langhi, 2021).

Considerando que uma das contribuições mais potentes da pesquisa de Lima e Langhi (2021) é a operacionalização de conceitos psicanalíticos na relação entre educadores e educandos, tomamos este espaço como um ensejo para discutir sobre as pertinências, usos e desusos da psicanálise na Educação em Ciências. A partir de reflexóes e apontamentos frutos do processo de arbitragem do trabalho supracitado e inspirados nos tempos lógicos de uma análise, ${ }^{2}$ em acordo com Lacan, dividimos o presente texto em três partes: instante de ver, tempo para compreender e momento de concluir. Na primeira parte, retomamos brevemente as relaçóes históricas entre psicanálise e educação, para depois recordarmos, em um instante de ver, um trabalho seminal para a exploração de analogias entre Educação em Ciências e Psicanálise (Villani, 1999). Na segunda parte, buscando um tempo para compreender, aprofundamos a discussão sobre a relação analógica entre os quatro discursos de Lacan e os discursos do professor de Ciências (Villani \& Barolli, 2006). Para isso, será necessário perscrutar as elaboraçôes do psicanalista francês sobre essa matéria e suas reverberaçôes quando direcionamos essas formas 
discursivas ao ato docente (Pereira, 2005). Por fim, adentramos nas interpretações de Lima e Langhi (2021) para discutir possíveis relações e o estabelecimento de um diálogo com vistas a um momento de concluir.

\title{
INSTANTE DE VER - PSICANÁLISE E EDUCAÇÃO (EM CIÊNCIAS)
}

\author{
"[...] a psicanálise não pode oferecer à pedagogia nenhuma metodologia. \\ Pois épelo avesso que ela a toma" (Voltolini, 2011, p. 71).
}

Aportes teóricos fundamentados na Psicanálise não são novidades na área de Educação, no entanto, quando comparados com contribuições oriundas de campos como a Sociologia e a Psicologia, a Psicanálise pouco contribuiu para os estudos dos fundamentos da Educação. Certamente a proposta de Sigmund Freud ao elaborar a teoria psicanalítica, a partir de 1900 podendo ser chamada dessa forma, foi reconhecida como uma contribuição extremamente importante para a cura dos adoecimentos psíquicos, entretanto, somente mais tarde, foi reconhecida pelo próprio Freud a relevância dessa descoberta para o campo da Educação. Inicialmente foram alguns de seus discípulos que problematizaram a educação sob a ótica das até então recentes elaborações psicanalíticas. Cabe ressaltar o papel de Sándor Ferenczi, que em 1908 proferiu uma conferência intitulada Pedagogia e Psicanálise e nela tecia críticas aos pedagogos de sua época e à escola, que na visão do psicanalista húngaro era um contexto de produção de pessoas neuróticas. No mesmo período, Freud já estabelecia um fértil diálogo com Oskar Pfister acerca das possíveis conexões entre Psicanálise e Educação, como no prefácio do livro A Psicanálise a Serviço dos Educadores em que o primeiro prevê a potencialidade do método psicanalítico na formação de educadores (Freud, 2010a). Da mesma maneira, posteriormente, destaca-se August Aichhorn que teve seu livro Juventude Abandonada também prefaciado por Freud. Nesse prefácio, Freud afirma ser a educação de crianças a aplicação da psicanálise que mais gerou interesse e esperanças entre os psicanalistas, bem como admite ser o espectro de uso da psicanálise no qual ele pouco contribuiu (Freud, 2011).

Como é possível presumir, embora Freud não tenha escrito nenhum texto específico sobre pedagogia e pouco ter contribuído diretamente com esse tema em específico, incentivou e sugestionou os trabalhos de muitos outros pesquisadores, tornando a educação da criança o principal objeto de investigação para vários psicanalistas. $\mathrm{Na}$ grande maioria desses trabalhos focalizou-se principalmente o campo dos afetos, de forma a complementar as metas da educação, ou seja, uma educação afetiva iria permitir que as crianças desenvolvessem uma sensibilidade relacional com os outros, podendo assim ir além do desenvolvimento de suas capacidades físicas e intelectuais (Pedroza, 2010). Nas últimas décadas, o cenário das relaçóes entre Psicanálise e Educação tem se alterado significativamente, principalmente com a psicanálise contemporânea e os avanços dos estudos na área de Educação (Cifalli, 1982; Millot, 1987; Kupfer, 1992; Lajonquière, 1999; Mrech, 1999; Imbert, 2001; Filloux, 2002; Voltolini, 2011, entre outros) O diálogo entre esses dois campos do saber, colocam em evidência uma interrogação sobre as novas formas de subjetividade, bem como sobre o entendimento de incertezas e éticas do ser humano (Pereira, 2005).

A nosso ver, uma grande contribuição desses trabalhos para a educação, e que gostaríamos de destacar, foi perceber a relação entre aprendizagem e transferência. ${ }^{3}$ Aprendemos com Freud que a transferência é o processo constitutivo do tratamento analítico e os desejos inconscientes do analisando, que se referem a objetos externos, passam a se repetir no âmbito da relação com o analista. Nessa relação o analista se empresta como objeto subjetivo e faz movimentar os afetos do analisando. Retomando a relação entre aprendizagem e transferência, temos que durante o processo de ensino haveria uma repetição da relação das crianças com os pais, desta vez envolvendo o professor, tornando-se objeto do amor. Muitas vezes Freud comparou a transferência com o amor. Daí o deslocamento das pesquisas psicanalíticas na tentativa de melhor compreender o papel do professor na educação das crianças e de auxiliá-las no exercício de suas atividades. Uma contribuição importante neste sentido foi o trabalho de Piera Aulagnier (1975), que apontou para a existência de uma 
dúplice violência exercida pela mãe sobre a criança durante os primeiros anos de cuidado. Para a autora, a violência primária, que consiste no conjunto de informações e ações transmitidas pela relação nos primeiros anos de vida, seria necessária para a criança entrar e interagir na sociedade; de modo contrário, a violência secundária seria o conjunto de informações e ações que vinculam a criança, engessam seu comportamento, impedindo que ela se desenvolva na relação com outros. Se consideramos que estas relações se repetem na relação do professor com a criança, percebemos a importância de as formas do professor explorar o investimento de amor da criança, portanto da transferência, seja para o desenvolvimento, seja para o bloqueio. Para explorar uma metáfora tradicional, o professor, para evitar os redemoinhos de "Caribdis", deverá cuidar de não ser devorado pelas fauces de "Cila”; ou seja, para evitar de sufocar o aluno com regras e informaçóes que o deixam sistematicamente sem escolhas (violência secundária), o professor não poderá deixá-lo perdido e sem critérios para realizar suas escolhas (violência primária).

Com o intuito de investigar as contribuições da psicanálise para o papel do professor, um grupo de pesquisadores da Universidade de São Paulo (USP), a partir da metade da década de 1990, focalizou as especificidades do professor de ciências e de sua relação com o ensino e a aprendizagem das ciências. Ao longo dessas quase três décadas, principalmente sob a influência do grupo de pesquisa supramencionado, alguns autores têm se debruçado na tarefa de estabelecer relaçóes entre os mais diversos conceitos psicanalíticos com a complexidade de ensinar e aprender Ciências. É possível afirmar que se trata de uma produção científica já consolidada na área, haja vista a disseminação de pesquisadores em diferentes universidades do país e a publicação de artigos nos principais periódicos da área.

A perspectiva de estabelecer conexões entre Psicanálise e Educação em Ciências foi explorada de diversificadas maneiras, principalmente no que se refere às temáticas e aos focos de estudo, como é possível perceber na breve sumarização a seguir:

- Relaçôes entre a psicanálise e as dificuldades no ensino de ciências a partir dos conceitos de transferência e inconsciente (Araújo, 1993);

- Interpretação do ensino e aprendizagem das Ciências por meio de analogias e metáforas, construídas a partir de resultados alcançados na Filosofia da Ciência, na História da Ciência e na Psicanálise (Villani et al., 1997);

- Analogias entre a estrutura dinâmica da mudança de um sujeito num processo psicanalítico e num processo de aprendizagem das ciências. (Villani \& Cabral, 1997; Villani, 1999);

- A partir de elementos da psicanálise lacaniana, construção de um esquema heurístico para a interpretação da relação do sujeito com sua aprendizagem escolar (Villani \& Barolli, 2000);

- Competência dialógica de um grupo de licenciadas em Biologia (Villani \& Franzoni, 2000);

- Motivaçóes e interesses na formação inicial de professores de Física (Arruda \& Ueno, 2003);

- Perfil subjetivo, ou seja, a posição subjetiva do aprendiz em relação ao conhecimento científico (Villani, Santana \& Arruda, 2003; Villani \& Santana, 2004);

- Aprendizagem significativa e o papel do desejo e da satisfação inconsciente na educação (Arruda et al., 2004);

- Análise do papel de uma professora de ciências no desenvolvimento de relaçóes intersubjetivas de um grupo de professores de uma escola (Valadares \& Villani, 2004);

- Dinâmica de grupos de aprendizagem de Física no ensino médio (Barros \& Villani, 2004);

- Os discursos do professor e a subjetividade na aprendizagem em Ciências (Villani \& Carvalho, 2005; Villani \& Barolli, 2006);

- Aspectos metodológicos da pesquisa em Educação em Ciências e as contribuições da psicanálise (Barolli, Valadares \& Villani, 2007; Villani et al., 2011); 
- Análise das modificaçóes no saber e na satisfação dos sujeitos envolvidos em uma experiência de colaboração entre universidade e escola (Barcelos \& Villani, 2006);

- Mudanças no discurso de um grupo de professoras de ciências do ensino fundamental no contexto da formação continuada (Barros et al., 2006);

- Análise do impacto da regência no estágio supervisionado em estudantes da licenciatura em Física a partir da metáfora do "professor como um lugar" (Arruda \& Baccon, 2007);

- Investigação da dinâmica de um grupo de aprendizagem em aulas de ciências a partir de conceituações de Pichon-Rivière (Barros, Laburú \& Rocha, 2007; Silva \& Villani, 2012);

- Práticas e discursos de uma formadora no processo reflexivo de professores de ciências (Altarugio \& Villani, 2010);

- A institucionalização da Pesquisa em Educação em Ciências no Brasil interpretada a partir da teoria de Kaës (Villani, Dias \& Valadares, 2010);

- Impasses em diferentes situações de sala de aula de Física e as posições assumidas pelos docentes (Villani, Barros \& Arruda, 2011);

- Discussão e reflexão sobre a formação de professores como uma metáfora a Lacan, mais especificamente as ideias de "desejo do docente" e "professor como um lugar”, em metáfora ao "desejo do analista” e "lugar do analista” respectivamente (Arruda \& Passos, 2012).

Um aspecto muito importante dessa produção foi a utilização de uma linguagem bastante clara e distante do discurso teórico dificilmente inteligível por um professor que não tenha formação no campo da psicanálise e, nesse sentido, o recurso da analogia mostrou-se particularmente promissor. A própria formação de um (psico) analista forneceu elementos para aprofundar uma concepção para a formação do professor, assim como as fases do processo de análise forneceram pistas para entender o processo de aprendizagem de um conteúdo científico.

\section{A EXPLORAÇÃO DE ANALOGIAS ENTRE PSICANÁLISE E EDUCAÇÃO EM CIÊNCIAS}

Em um artigo seminal publicado nesta revista há mais de 20 anos, e que se mostrou frutífero ao longo dos anos, as contribuiçôes das analogias entre Psicanálise e Educação em Ciências foram sintetizadas, mais especificamente as relações entre o processo de formação de um analista e de um professor de Ciências (Villani, 1999). Grosso modo, tanto a formação do professor quanto a formação do analista são entendidas como envolvendo necessariamente dois componentes: um de caráter teórico e outro experiencial. A primeira caracterização é semelhante à formação de qualquer especialista, consistindo principalmente no estudo teórico por meio do contato com as obras dos principais autores e participação em contextos nos quais se discute casos com colegas, mais experientes ou não. No que se refere ao componente experiencial, a formação do analista parece fornecer elementos importantes para a formação de professores.

A formação de um analista ${ }^{4}$ tradicionalmente é caracterizada por um tripé, o qual é composto pela formação teórica, análise pessoal e supervisão clínica. É consensual que a base dessa formação, ou seja, o passo mais importante é a realização de uma análise pessoal até seu término específico. É nessa travessia da análise individual que o sujeito tem acesso a um tipo de saber ao qual não se tem por meio do estudo teórico e tampouco com a supervisão clínica dada por um analista mais experiente. De acordo com Freud, trata-se dos efeitos que se fazem sentir "na própria pele", a partir de uma mudança de posição de paciente a analista operada por um ato psicanalítico, com a destituição subjetiva e a travessia da fantasia no fim da análise. "O ato psicanalítico é o ato realizado a partir do advento do sujeito como objeto, quando o sujeito se destitui como analisante para instituir-se como analista, podendo suportar bancar o objeto causa de desejo para um analisante” (Quinet, 2009, p. 96). 
Muitas vezes iniciar uma análise implica para o sujeito procurar conhecer melhor a si mesmo, no entanto este início não é o mais favorável, pois constitui uma fuga no enfrentamento dos problemas que originam suas insatisfaçóes. Assim, a primeira operação do analista seria transformar a demanda do analisando numa espécie de pedido de ajuda que coloque seu "analista na posição de Sujeito Suposto Saber, ou seja, de alguém que sabe trabalhar/manejar a insatisfação do analisando e no qual, então, este pode confiar" (Villani, 1999, p. 15). Essa dinâmica na relação analista-analisando cria o que chamamos de transferência imaginária, relação na qual o sujeito imagina que o Outro resolverá suas inquietaçôes. Uma situação semelhante pode ser observada na formação de um professor, onde o futuro professor pode se encantar por algum conteúdo científico, desejar aprendê-lo e transmiti-lo para outros sem dificuldades. No entanto, este início esconde a necessidade de mudança do sujeito que aprende e que deveria colocar seu professor formador na condição de Outro, selando uma dependência semelhante à da transferência imaginária. Um convite sedutor do professor formador pode ajudar a motivação do licenciando, mas o efeito não será duradouro se não for transformado numa percepção das dificuldades de mudar sua visão da ciência e no pedido de ajuda para o formador. De forma análoga, as outras fases da formação do analista ajudam a complementar o caminho do futuro professor: investir na elaboração do conhecimento com o guia do professor formador.

O ponto de virada seria o reconhecimento de que a aprendizagem do conteúdo científico não é uma repetição, mas uma reelaboração que organiza todo seu conhecimento, assim como numa análise, em que o sujeito é sustentado pelo analista para assumir a responsabilidade de suas escolhas. A analogia continua funcionando porque tanto o processo de análise quanto o de aprendizagem têm como estratégia básica a escuta do outro, apesar de se tratar de formas diferentes em cada caso: a fala livre do analisando permite o aparecimento de bloqueios inconscientes (mecanismos de defesa) e a conquista de seus desejos; e o diálogo na aprendizagem permite o aparecimento de noções espontâneas e de buscas originais em direção a novos conhecimentos.

Nessa perspectiva, o processo de análise termina ${ }^{5}$ quando o sujeito para de prestar conta para o Outro, inclusive o analista, assumindo a responsabilidade de suas escolhas e ganhando autonomia; por isso em condiçôes de ajudar outros a percorrerem o mesmo caminho. Na aprendizagem das ciências o aprendiz também será professor quando tiver elaborado o conhecimento científico numa síntese própria que o tornará capaz de auxiliar os educandos a construírem seus sentidos. Em resumo, a possibilidade de utilizar de forma analógica o percurso de uma análise para entender o movimento do processo de aprendizagem se baseia fundamentalmente no paralelo entre vários momentos significativos, de um lado, recusa do problema psíquico, instauração da transferência imaginária, entrada na transferência simbólica e separação e, de outro lado, recusa do novo conhecimento, demanda passiva, aprendizagem ativa e busca independente.

Com intuito de dialogar com as análises realizadas por Lima e Langhi (2021), sobretudo no que concerne aos discursos do inconsciente lacaniano, principal recurso teórico utilizado pelos autores na compreensão da relação transferencial entre professoras monitoras e crianças no contexto de um observatório astronômico, a seguir aprofundamos nos quatro discursos lacaniano e o ato docente.

\title{
TEMPO PARA COMPREENDER - OS QUATRO DISCURSOS DE LACAN E O ATO DOCENTE
}

\author{
"Como há muito já reconheci que provocar oposiz̧ão e despertar o rancor éo \\ destino inevitável da psicanálise" (Freud, 1996, p. 17).
}

Em Análise terminável e interminável, Freud (2018) é bastante contundente ao afirmar que existiam três ofícios os quais eram impossíveis, quais sejam, governar, educar e curar. A impossibilidade desses fazeres, para Freud, estaria relacionada com uma característica intrínseca e comum a esses of ícios, o de serem exercidos pelo engajamento da palavra. A palavra, em última instância seria um instrumento falho, dizer toda a verdade está no 
campo da impossibilidade, justamente porque nos faltam as palavras. "Sempre digo a verdade: não toda, porque dizê-la toda não se consegue. Dizê-la toda é impossível, materialmente: faltam palavras. É por esse impossível, inclusive, que a verdade tem a ver com o real. (Lacan, 2003b, p. 508). Na esteira dessa particularidade, Lacan introduz um quarto fazer impossível, o de fazer desejar, ou seja, a tarefa do psicanalista de sustentar o processo do analisando em relação a seu próprio desejo. Associadas a essas práticas sociais impossíveis, Lacan (1992), em seu Seminário 17 - O avesso da psicanálise, lança mão de algoritmos para teorizar sobre os discursos do inconsciente. Nessa perspectiva, a seguir apresentaremos alguns apontamentos sobre os quatro discursos de Lacan (1992), bem como sua relação com os discursos do professor (Villani \& Barolli, 2006) e o ato docente (Pereira, 2005).

A teorização de Lacan sobre os quatro discursos tem sido considerada como um dos instrumentais mais férteis para a psicanálise, haja vista que focaliza sobre aquilo que o sujeito produz em seus vínculos ou laços sociais. Cabe salientar que sujeito para a psicanálise é o sujeito do inconsciente, ou seja, o ser dependente da linguagem em que um significante o representa e, portanto, o determina diante de todos os outros. Enquanto a linguagem é estruturante dos laços sociais, o discurso do inconsciente é a maneira do sujeito revelar-se diante do desenvolvimento dos laços sociais, como manifestação de uma busca por uma falta intrínseca, da ordem do não assimilável, do não representável e do não explicável. Assim, os sujeitos criam laços não por processos identificatórios, mas sim pela busca por escapar daquilo que Freud chamou de "mal-estar".

Como já destacado, sob a forma de algoritmos, ou esquemas algébricos denominados mathemas, Lacan (1992) propóe os quatro discursos: o discurso do mestre, do universitário, do analista e da histérica. É possível presumir que esses quatro discursos correspondem às práticas sociais ditas anteriormente como impossíveis, governar, educar, psicanalisar e fazer desejar. A estrutura proposta pelo psicanalista francês se define por quatro "lugares", ou quadrantes fixos que correspondem ao agente do discurso, lugar do outro, produção (ou perda) e verdade, esquematicamente organizado conforme a Figura 1.

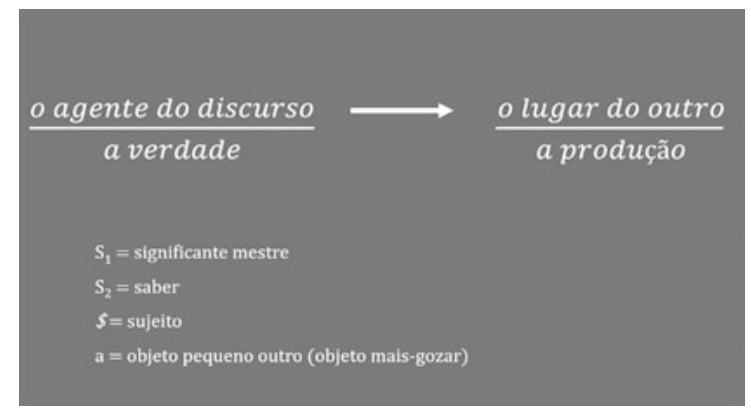

\section{Figura 1. Estrutura de posições dos discursos de Lacan e seus elementos}

Nessa estrutura o agente é aquele que organiza o discurso e domina o laço social, ou seja, é o responsável por modular o discurso e possibilitar a alteridade. O outro, por sua vez é aquele a quem o discurso é direcionado, portanto, necessita do agente para se constituir. A produção é o efeito ou resultado do discurso, pode ser aquilo que resta ou se perde. A verdade sustenta o discurso e é acessível somente por aquilo que não é dito explicitamente, em outras palavras, pelo "semi-dito", que se encontra velado nos laços sociais. De maneira sintética, "todo discurso pressupóe um agente - que fala a partir de sua verdade - e um outro - a quem o discurso se destina -, que na estrutura discursiva irá, eventualmente, produzir algo de acordo com aquilo que o agente lhe demandar" (Villani \& Barolli, 2006, p. 157).

Como elementos têm-se o significante mestre $\left(S_{1}\right)$, o saber $\left(S_{2}\right)$, o sujeito dividido $(\$)$ e o objeto $(\mathrm{a})$. O significante mestre é aquele que inscreve a lei, que representa o sujeito como atravessado e determinado pelo significante. No entanto, é um significante vazio de significação. O saber é o significante que dá significação ao $S_{1}$, portanto, designa a cadeia de saber que estrutura o inconsciente, para a psicanálise, um saber que não se 
sabe. O sujeito, dividido pelo efeito da linguagem, marcado pela barra, portanto barrado, representa o sujeito do vir a ser. Por fim, o objeto a é o objeto causa de desejo ou o objeto mais-gozar. Como causa do desejo é o objeto perdido na inscrição da lei (castração), representa a falta e impulsiona o sujeito na busca pelo desejo. Como mais-gozar representa a busca pelo impossível, pela recuperação da experiência de um gozo perdido.

Os quatro discursos se estruturam de maneiras diferentes, conforme as posições dos elementos nos quadrantes e sua formulação toma o discurso do mestre como ponto de partida (Figura 2).

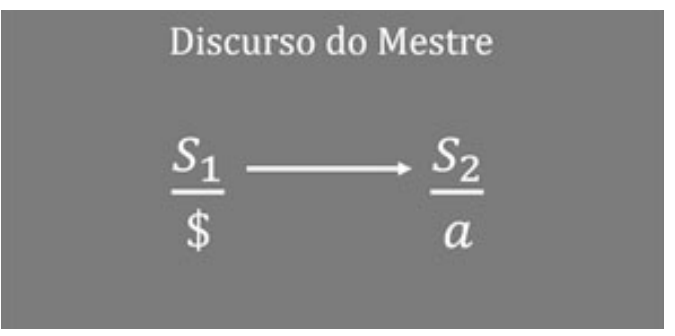

Figura 2. Estrutura do discurso do mestre

No discurso do mestre a posição do agente é ocupada pelo significante mestre $\left(\mathrm{S}_{1}\right)$, nesse sentido, representa o lugar da lei. Assim, o mestre "deve ser obedecido - não porque nos beneficiaremos com isso ou por alguma outra razão desse tipo - mas porque ele assim o diz” (Fink, 1998, p. 161). A posição de plenitude do mestre "esconde", ou mais precisamente, recalca, uma verdade incontornável: a divisão do sujeito $(\$)$, em outras palavras, sua incompletude, suas insatisfações.

$\mathrm{O}$ mestre $\left(\mathrm{S}_{1}\right)$ dirige-se ao escravo $\left(\mathrm{S}_{2}\right)$, que está situado na posição do trabalhador (posição do outro). $\mathrm{O}$ escravo, ao trabalhar duro para o mestre, aprende algo: ele vem encarnar o saber (saber entendido como algo produtivo), representado aqui por $\mathrm{S}_{2}$. O mestre não se preocupa com o saber: contanto que tudo funcione, contanto que seu poder seja mantido ou aumente, tudo está bem. [...] Considerando o capitalista como mestre e o trabalhador como escravo, o objeto (a) que aparece no canto direito inferior representa o excedente produzido: a mais-valia. Esse excedente, derivado da atividade do trabalhador, é apropriado pelo capitalista e poderíamos presumir que ele, direta ou indiretamente, proporciona algum tipo de prazer a este último: o mais-gozar. O mestre não pode mostrar nenhuma fraqueza e, consequentemente, oculta com cuidado o fato de que ele, como qualquer um, é um ser da linguagem que sucumbiu à castração simbólica: a divisão entre o consciente e o inconsciente $(\$)$ acarretada pelo significante é velada no discurso do mestre e aparece na posição de verdade: a verdade dissimulada (Fink, 1998, p. 161).

A proposição de Villani e Barolli (2006), ao explorar analogias entre os discursos de Lacan e os discursos do professor de Ciências em sala de aula, permite interpretar a prática docente a partir das posiçóes implícitas que o professor assume em seu ato de educar. Nesse processo analógico, o professor é sempre colocado no lugar de agente do discurso, produzindo diferentes laços em acordo com a posição implícita que ocupa em relação aos alunos e aos saberes relacionados aos conhecimentos científicos e didático-pedagógicos. No discurso do mestre, podemos imaginar então, grosso modo, que o professor assume o lugar de agente do discurso $\left(\mathrm{S}_{1}\right)$, ou seja de "uma posição a partir da qual está investido plenamente de um conhecimento soberano que determina a maneira pela qual as coisas funcionam ou devem funcionar" (Villani \& Barolli, 2006, p. 160). No lugar de agente, o professor se dirige ou demanda algo ao outro, aos alunos $\left(\mathrm{S}_{2}\right)$, no sentido de que estes produzam saberes científicos. Neste discurso, o professor está na posição de um agente sustentado pela crença de que tudo sabe, no entanto, o lugar da verdade esconde o fato de que ele está dividido $(\$)$, de que seu conhecimento é inevitavelmente incompleto. Segundo os autores, esse discurso se configura como muito sedutor, uma vez que o aluno, ao aceitar estabelecer esse vínculo, "poderá experimentar colocar a seu serviço um conhecimento que lhe trará satisfação” (Villani \& Barolli, 2006, p. 161). 
Com um quarto de giro dos elementos pelas posições chega-se ao discurso da universidade, também conhecido como discurso universitário, da instituição ou do burocrata (Figura 3). Nesse discurso, o lugar de agente é ocupado pelo saber $\left(\mathrm{S}_{2}\right)$ que se dirige a um outro objetivado (a). Trata-se de um saber sistemático, um saber como autoridade máxima que, segundo Fink (1998), trabalha a serviço do significante-mestre $\left(S_{1}\right)$, servindo qualquer tipo de argumentação, desde que assuma o disfarce da razão e da racionalidade. $O$ produto no discurso da universidade é um sujeito barrado (\$), que na sua incompletude deseja saber mais.

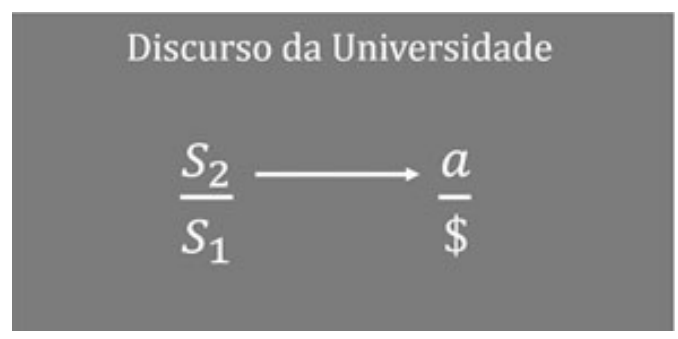

Figura 3. Estrutura do discurso da universidade

Para Villani e Barolli (2006), trata-se do discurso em que o sujeito está comprometido com uma espécie de dogma, crença que o sustenta e que é razão de sua existência. Como um conservador e veiculador dos saberes de grandes autores, no discurso da universidade o professor de Ciências autoriza-se de um saber científico $\left(\mathrm{S}_{2}\right)$ para impor esse saber ao outro objetivado, o estudante (a), tornando-se, portanto, o "guardião da letra alheia na impotência de inscrever a sua própria” (Pereira, 2005, p. 107). Um professor de ciências que desenvolve um laço com seus estudantes por meio desse discurso é tido como aquele que é porta-voz do conhecimento científico e dogmático, não restando outra opção ao estudante a não ser a submissão. Como produto desse ato docente, o que se tem é um estudante dividido e alineado $(\$)$, que, com sua culpa, não se sente adequado no atendimento da demanda e alienado neste saber dogmático.

Se, no ensino de ciências, o aluno aceitar se submeter a esse discurso, ele se constituirá num sujeito que anseia por esse conhecimento, mas ao mesmo tempo se sentirá sempre excluído, pois, implicitamente, percebe a impossibilidade de alcançar a sapiência que lhe é demandada. No entanto, esse discurso, ao fazer laço nas situações de ensino, cria condiçôes para que o aluno almeje se apropriar do conhecimento científico e, assim, de alguma forma, manter um esforço na aprendizagem (Villani \& Barolli, 2006, p. 165).

Completamente em oposição ao discurso da universidade, o discurso da histérica ocupa um papel de muita importância para a psicanálise, haja vista que foi a partir de sua escuta que Sigmund Freud "descobriu” o inconsciente. Nesse discurso, quem está no lugar de agente é o sujeito dividido ( $\$$ ), a histérica e seu sintoma, que dirige sua demanda ao significante-mestre $\left(\mathrm{S}_{1}\right)$, com a suposição de produzir um saber $\left(\mathrm{S}_{2}\right)$, saber este acerca de sua própria divisão, seu sintoma. Em contrapartida a saber, encontra-se o objeto (a) no lugar da verdade. "Sua verdade é que precisa ser objeto a para ser desejada" (Lacan, 1992, p. 167). (Figura 4).

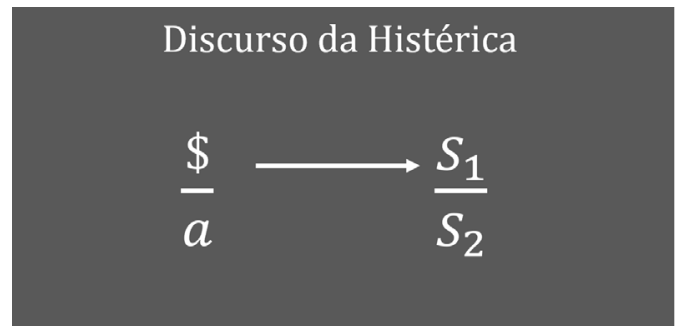

Figura 4. Estrutura do discurso da histérica 
Identificado por Lacan como o discurso da Ciência, o discurso da histérica é instituído pelo desejo de saber, portanto um discurso caracterizado por uma espécie de insatisfação. Nesse discurso, o professor $(\$)$ dirige-se ao estudante $\left(\mathrm{S}_{1}\right)$ reconhecendo sua incompletude, isto é, reconhece sua falta, a qual é justamente o que o caracteriza como agente (Villani \& Barolli, 2006). Em termos da analogia, um professor de Ciências em seu ato docente, ao estabelecer o laço com os estudantes, promoverá condiçôes para que os aprendizes sintam prazer em perceber sua incompletude em relação aos conhecimentos científicos e, consequentemente, ir além daquilo que já sabem. Assim como o discurso da histérica tem lugar fundamental para a psicanálise, pois é o discurso chave do processo de cura psicanalítica, para a analogia proposta por Villani e Barolli (2006), ocupa um papel importante nos processos de ensino e aprendizagem, haja vista que dá condiçóes para que o aluno, a partir do ensino, possa alcançar um saber que lhe é próprio, mas que tem como referência o saber científico veiculado pelo professor.

No polo oposto ao discurso do mestre, tem-se o discurso do analista, em que o agente é o desejo inconsciente, objeto (a), a causa do desejo. Nas palavras de Lacan (1992, p. 36), "ele, o analista, se faz causa do desejo do analisante”. O analista em seu ato analítico desempenha uma função desejante e interroga o outro, o sujeito na sua divisão $(\$)$, até que este trabalhe, associe e produza um novo significante-mestre $\left(\mathrm{S}_{1}\right)$. A verdade nesse discurso é ocupada pelo saber $\left(\mathrm{S}_{2}\right)$, que é caracterizado por uma espécie de enigma, um semidito (Figura 5).

O discurso do analista é o único em que o saber advém no lugar da verdade. Nesse sentido, o discurso do analista além de se referir à posição do analista na condução de uma cura, descreve também o discurso do sujeito marcado pela travessia de uma análise. Sujeito que, tendo passado pela experiência radical da falta, a partir da destituição do sujeito suposto saber, tem o objeto a, em sua vertente de causa de desejo agenciando o seu discurso e um saber construído sobre a verdade de seu desejo. Assim, se produz na versão lacaniana sobre o final de análise um analista. (Penna, 2003, p. 95).

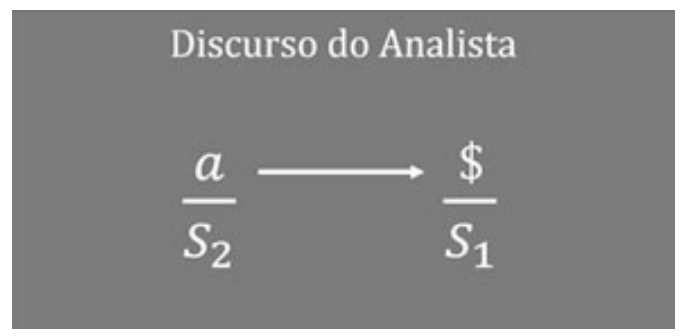

Figura 5. Estrutura do discurso do analista

No que concerne à analogia proposta por Villani e Barolli (2006), o discurso do analista pressupóe situações de ensino em que o professor, em seu ato docente, crie condiçóes para que o estudante caminhe em busca de sua própria autonomia. Não é difícil presumir que este seja o discurso almejado em um processo de ensino com vistas ao amadurecimento do aprendiz na busca pela própria aprendizagem em uma perspectiva crítica. Nesse discurso o professor no lugar de agente, no lugar de objeto causa do desejo (a), é o sujeito que se interroga sobre sua própria falta e é sustentado por um tipo de saber que ocupa o lugar da verdade $\left(\mathrm{S}_{2}\right)$. Ao dirigir-se ao outro, o estudante em sua indiferença $(\$)$, um sujeito de desejo, tem-se como produção a autonomia na busca pelo conhecimento $\left(S_{1}\right)$.

Neste tempo para compreender, ao menos aproximativamente, a teorização sobre os quatro discursos proposta por Lacan (1992), bem como as consideraçôes de Villani e Barolli (2006) em torno das analogias com os discursos do professor de Ciências em seu ato docente (Pereira, 2005), podemos pensar em alguns apontamentos. Primeiramente, que em qualquer processo de ensino e aprendizagem, o mais importante é que o professor consiga alternar os discursos e "essa alternância poderá ser conduzida pela progressiva revelação da verdade do agente ou pelo efeito provocado pelo aluno” (Villani \& Barolli, 2006, p. 172). A fixação do professor em estruturas discursivas como a do mestre, da universidade e da histérica, pode induzir o engessamento do poder criativo dos estudantes. Por sua vez, com vistas a um ensino promotor de autonomia, que ultrapasse 
qualquer tipo de rigidez e inflexibilidade, o discurso do analista nos parece ser aquele com maior potencial de inventividade para o professor, haja vista sua estrutura de um sujeito de desejo no lugar do outro $(\mathrm{a} \rightarrow \$)$. Além disso, é importante que a passagem do professor pelos diversos discursos se inicie pelo discurso do mestre, tendo em vista que é nesse discurso que se instaura o traço da lei, inaugura o significante primeiro $\left(\mathrm{S}_{1} \rightarrow\right.$ $\mathrm{S}_{2}$ ). Como já destacado, a necessidade da alternância entre os discursos pressupóe que o professor não fique preso nesse primeiro discurso, mas "deve se utilizar do discurso do mestre para não permanecer ali" (Pereira, 2005, p. 110). Se lembrarmos que os discursos do mestre e da universidade produzem o controle do aprendiz, ao passo que os discursos da histérica e do analista favorecem a aprendizagem, parece essencial que a gestão dos discursos por parte do professor instaure uma violência primária sem se fixar numa violência secundária.

Os autores do trabalho que estamos comentando optaram pelo referencial teórico psicanalítico para analisar as falas de monitoras e crianças na visita a um observatório astronômico. O trabalho sem dúvida é importante por tratar de um tema ainda pouco explorado: a iniciação científica das crianças antes do início da escola formal. O interesse é ainda maior tendo presente o conteúdo científico tratado (a astronomia) e o instrumental de análise escolhido, os discursos de Lacan.

\title{
MOMENTO DE CONCLUIR-OBSERVANDO O INVISÍVEL
}

\author{
"[...] a pressa é amiga da conclusão" (Quinet, 2009, p. 64).
}

A pesquisa de Lima e Langhi (2021, p. 2) contribuiu para que "o trabalho de divulgação da astronomia com crianças e a relação com o saber na educação não-formal" se torne a "base e um dos meios para compreendermos os processos de iniciação do letramento científico”. Também consideramos que o referencial teórico adotado contribuiu para a realização de uma interpretação original. Trata-se de um referencial muito favorável para aprofundar a relação linguística entre estudantes e monitoras, pois focaliza a relação transferencial, essencial para o processo de aprendizagem. Assim, consideramos pertinente a apresentação das várias intervenções das monitoras, pois permitem perceber o efeito dos discursos utilizados, tanto pelas monitoras quanto pelas crianças.

Por meio de observação, gravações em audiovisual e registros em caderno de campo, Lima e Langhi (2021) coletaram informações sobre uma visitação de um grupo de crianças da educação infantil em um observatório astronômico, sob a mediação de duas educadoras. Os discursos veiculados pelas monitoras foram analisados sob a luz da psicanálise lacaniana, mais especificamente por meio da mobilização dos conceitos de transferência e dos quatro discursos de Lacan. Em linhas gerais, as análises realizadas evidenciam a diversidade de discursos na relação transferencial entre monitoras e crianças, tais como o discurso da universidade (instituição), discurso da histérica e discurso do mestre. Os autores ainda, estabelecem uma relação de síntese entre os discursos e enfoques que delineiam a demanda entre crianças e monitores.

Retomando a exploração de analogias entre o percurso de uma análise e o processo de aprendizagem em ciências, consideramos que é possível avançarmos ainda mais, focalizando as estratégias que o analista pode utilizar para guiar o analisando nas passagens entre os vários momentos em uma análise. Lacan lançou mão dos discursos do inconsciente como ferramentais importantes para a condução do ato psicanalítico. O discurso do mestre seria um recurso importante para convencer (ou até seduzir) o analisando de que uma análise seria uma boa experiência; o discurso da universidade poderá ser utilizado para confirmar ao analisando de que este encontra-se no processo analítico (ou, ao contrário, de que não está respeitando as regras); o discurso da histérica pode ser utilizado para questionar o analisando de que este pode investir mais e se responsabilizar mais por suas escolhas; finalmente, o discurso do analista pode servir para indicar que a análise está terminando. Naturalmente estas possibilidades supóem que o analisando aceite se colocar na posição indicada pelo discurso. De forma análoga, no campo da aprendizagem das ciências por meio do ato docente, o discurso do mestre é um instrumento fundamental para o abandono da recusa a apreender e a entrada na demanda passi- 
va; o discurso da universidade é importante para a confirmação ou negação da relação dos aprendizes com o conhecimento; o discurso da histérica é essencial para a entrada ou a estabilização na aprendizagem ativa; e por fim, o discurso do analista introduz e reforça o aprendiz na busca independente do conhecimento.

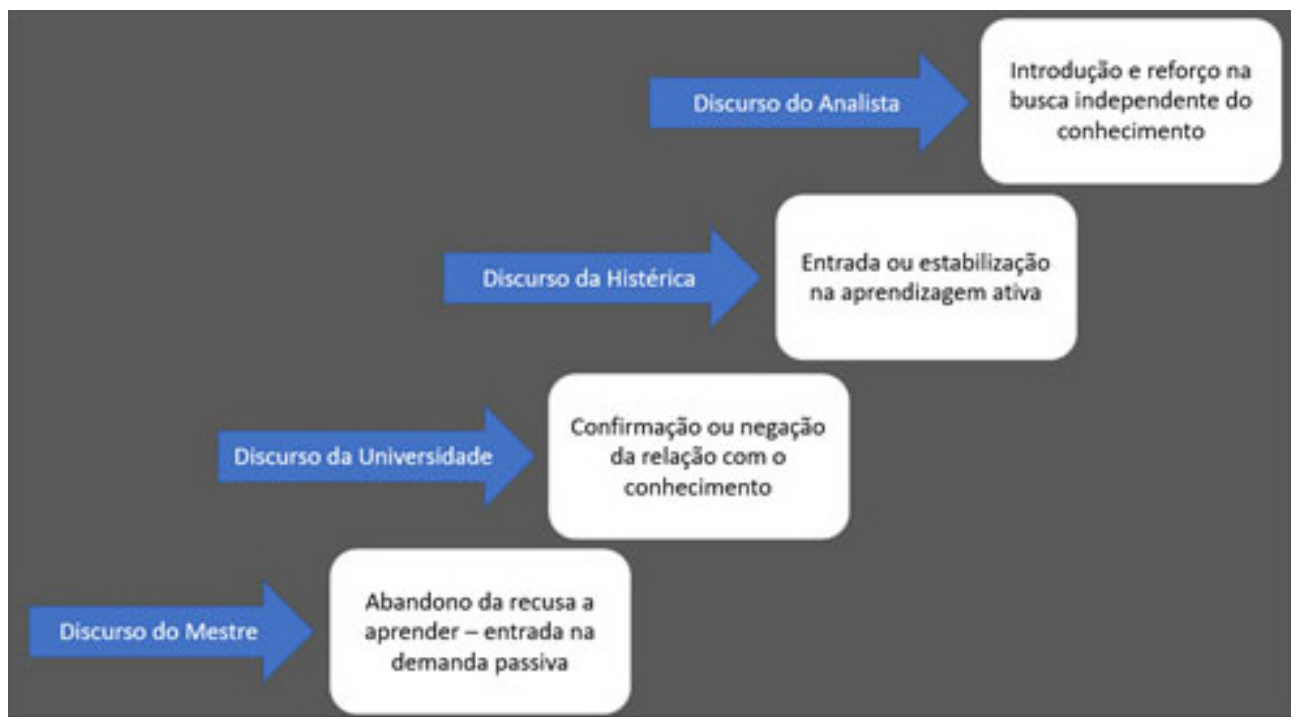

Figura 6. 0 papel dos discursos nas etapas da aprendizagem em ciências.

Nas análises trazidas por Lima e Langhi (2021), as interações discursivas entre as professoras monitoras e crianças perpassam basicamente por três tipos de discurso, do mestre, da universidade e da histérica, não se fixando demasiadamente em nenhum deles. Na primeira parte da visitação das crianças ao observatório astronômico, por meio de diversos questionamentos, foi solicitado que os aprendizes explicitassem livremente seus conhecimentos prévios acerca da astronomia. Como resultado, por meio do discurso da histérica, estabeleceu-se um laço com as crianças que se entusiasmaram com a dinâmica e tiveram a oportunidade de falar livremente, demonstrando a confiança necessária nas educadoras, terreno fértil para o estabelecimento da transferência. "É por isso que transferência é amor, sentimento que assume aí uma forma tão nova, que esta introduz a subversão, não porque seja menos ilusória, mas porque dá a si um parceiro que tem a chance de responder, o que não acontece nas outras formas" (Lacan, 2003c, p. 555). A fala livre das crianças abre espaço para que a linguagem entre em cena, como um tonel que vaza. "É por escapar (no sentido do tonel) que um discurso adquire seu sentido, ou seja, pelo fato de seus efeitos serem impossíveis de calcular" (Lacan, 2003c, p. 550).

Em um segundo momento da visitação, uma das professoras monitoras queria que as crianças aprendessem que o Sol e as estrelas são objetos com as mesmas características, apesar da aparência diferente. Assim, ela iniciou com um questionamento sobre o saber das crianças a respeito e conseguiu conduzir uma discussão com o envolvimento dos aprendizes. Uma característica dessa condução foi o deslizamento para diferentes tipos de discursos, dependendo da fala das crianças, passando pelos discursos da histérica, do universitário e do mestre. O discurso da histérica, caracterizado pela instituição do desejo de saber e a assunção de uma incompletude em relação aos conhecimentos científicos, nos parece ter sido o patamar mais avançado atingido pelas monitoras nas interaçóes discursivas, haja vista que possibilitou que as crianças entrassem em uma aprendizagem ativa ao serem confrontadas com um novo conhecimento. No entanto, a nosso ver, as monitoras não conseguiram sustentar uma passagem do discurso da histérica para o discurso do analista, com vistas em promover a introdução das crianças em uma busca independente do conhecimento. Sem dúvida, esta não é uma tarefa muito trivial, principalmente se considerarmos o contexto das interaçôes, uma visitação em um observatório astronômico.

O que se observou nos momentos seguintes da visitação, ao contrário, foi o deslizamento, e em alguns momentos a fixação, no discurso da universidade, objetificando (a) as crianças por meio de um discurso auto- 
ritário, não lhes restando outra opção a não ser a submissão. Na discussão sobre os planetas, a condução favorecia a repetição por parte dos alunos daquilo que a monitora falava, resultando apenas em respostas aleatórias. Compreendemos que o discurso do mestre, convidando as crianças a uma viagem emocionante para os vários planetas, seria muito mais efetivo se explorasse os exemplos das viagens espaciais realizadas pelos astronautas, sejam aquelas que ocorreram ao longo da história, sejam aquelas que acontecem atualmente. Nos parece que o diálogo sobre a viagem para o Sol tinha esta expectativa, no entanto, não encontrou respaldo nos conhecimentos das crianças, tornando-se um debate em boa parte sem sentido, não consolidando um laço pelo discurso.

$\mathrm{Na}$ análise de Lima e Langhi (2021), o discurso da histérica foi o predominante ao longo da visitação das crianças ao observatório, haja vista que, na relação discursiva, todos estavam imbuídos em adentrarem na cultura científica e, portanto, perpassavam por discursos caracterizados pela insatisfação e inquietação. No entanto, o que se observou em alguns momentos, foram demandas distintas entre as professoras monitoras e as crianças, enquanto estas estavam interessadas nos desenhos, nas cores, nos foguetes; aquelas demandavam os conhecimentos científicos da astronomia, muito distantes dos universos daqueles aprendizes. Portanto, alguns questionamentos se fazem necessários: com esse descompasso entre as demandas subjetivas, podemos falar em discurso do mestre? Nesse caso, de fato houve laço?

Em resumo, o artigo explicita de forma clara que o efeito da transferência sobre as crianças depende fundamentalmente da articulação entre os discursos para que não se perca o laço. Os diálogos sugerem que não existe um discurso dominante que possa garantir este laço, o que importa é a presença de intervenções que impeçam o esvaziamento do diálogo e a fixação demasiada em apenas um dos discursos (exceto o discurso do analista). Quando o discurso da histérica não é sustentado por um correspondente discurso da universidade ou do mestre, que forneça informaçóes a serem questionadas, a interação pode se tornar aleatória e sem o estabelecimento de um laço profícuo a aprendizagem. De forma semelhante, se o discurso da universidade não é interrompido por questôes que permitam aos alunos revelar sua efetiva participação, o resultado é bem limitado, como foi possível observar em várias intervençôes das monitoras na visitação ao observatório.

Finalmente, achamos muito importante as considerações trazidas por Lima e Langhi (2021), apontado para os três enfoques diferentes utilizados pelas monitoras: o enfoque do autoritarismo, o enfoque da excitabilidade e o enfoque da alteridade. Uma interpretação e articulação possível, seria pensar estes enfoques como meios de se transpor de uma forma de discurso a outro, ou até mesmo de uma etapa de aprendizagem a outra. Sendo a superação do enfoque do autoritarismo uma forma de passar do discurso do mestre para o discurso da universidade e assim possibilitar o estudante a experimentar uma relação diferenciada e compromissada com o conhecimento. $\mathrm{O}$ enfoque da excitabilidade seria a passagem do discurso da universidade para o discurso da histérica, proporcionado ao aluno a entrada ou estabilização em uma aprendizagem ativa. Por fim, o enfoque da alteridade seria a relação mais preocupada com a construção do saber no campo do outro, ou seja, a passagem do discurso da histérica para o discurso do analista e, consequentemente, a introdução do aprendiz em uma busca autônoma e responsável pelo conhecimento. Nessa perspectiva, estes enfoques são formas diferentes de apresentar o conteúdo dos discursos da psicanálise e constituem uma interpretação da função da fala, para além da comunicação.

\section{REFERÊNCIAS}

Altarugio, M. H. \& Villani, A. (2010). O papel do formador no processo reflexivo de professores de Ciências. Investigaçôes em Ensino de Ciências, 15(2), 385-401.

Araújo, A. T. S. Psicanálise e ensino. (1993). Cad. Cat. Ens. Fis., 21, 243-246.

Arruda, S. M. \& Baccon, A. L. P. (2007). O professor como um "lugar": uma metáfora para a compreensão da atividade docente. Ensaio. Pesquisa em Educação em Ciências, 9(1), 112-131. 
Arruda, S. M. \& Passos, M. M. (2012). Da Psicanálise ao Ensino de Ciências: o "desejo do docente" e o "professor como um lugar". Ciência छ̇ Educação, 18(1), 69-80.

Arruda, S. M. \& Ueno, M. H. (2003). Sobre o ingresso, desistência e permanência no curso de Física da Universidade Estadual de Londrina: algumas reflexóes. Ciência $\Xi^{2}$ Educação, 9(2), 159-175.

Arruda, S. M., Villani, A., Ueno, M. H. \& Dias, V. S. (2004). Da aprendizagem significativa à aprendizagem satisfatória na educação em Ciências. Cad. Cat. Ens. Fis., 13(2), 235-251.

Associação Mundial de Psicanálise. (1995) Como terminam as análises: textos reunidos. Rio de Janeiro: Jorge Zahar.

Aulagnier, P. (1975). A violência da interpretação: do pictograma ao enunciado. Rio de Janeiro: Imago.

Barcelos, N. N. S. \& Villani, A. (2006). Troca entre universidade e escola na formação docente: uma experiência de formação inicial e continuada. Ciência $\Xi$ Educação, 11(1), 73-97.

Barolli, E., Valadares, J. M. \& Villani, A. (2007). Explicitando uma metodologia de pesquisa: a experiência de uma professora de Física revisitada. Ciência छ̊ Educação, 13(2), 253-271.

Barros, M. A. \& Villani, A. (2004). A dinâmica de grupos de aprendizagem de Física no ensino médio: um enfoque psicanalítico. Investigą̧ôes em Ensino de Ciências, 9(2), 115-136.

Barros, M. A., Laburú, C. E. \& Rocha, Z. F. D. C. (2007). Análise do vínculo entre grupo e professora numa aula de ciências do ensino fundamental. Ciência $\Xi^{\circ}$ Educação, 10(2), 197-217.

Barros, M. A., Arruda, S. M., Laburú, C. E., Batista, M. C. \& Silva, A. I. (2006). Entre a queixa e a reflexão: a promoção de mudanças no discurso de um grupo de professoras de Ciências no ensino fundamental. Ensaio. Pesquisa em Educação em Ciências, 8(2), 132-145.

Cifalli, M. (1882). Freud pédagogue? Psychanalyse et éducation. Paris: Inter Editions.

Ferenczi, S. (2011a). Transferência e introjeção. In: S. Ferenczi. Psicanálise I. (pp. 87-123). São Paulo: WMF Martins Fontes. (Trabalho originalmente publicado em 1908).

Ferenczi, S. (2011b). O problema do fim da análise. In S. Ferenczi. Psicanálise IV. (pp. 17-27). São Paulo: WMF Martins Fontes. (Trabalho originalmente publicado em 1928).

Filloux, J. C. (2002). Psicanálise e Educação. São Paulo: Expressão \& Arte.

Fink, B. (1998). O Sujeito Lacaniano - entre a linguagem e o gozo. Rio de Janeiro: Jorge Zahar Editor.

Freud, S. (1996). A história do movimento psicanalítico. In S. Freud. Edição standard das obras psicológicas completas de Sigmund Freud. (pp. 14-73). Rio de Janeiro: Imago. (Trabalho originalmente publicado em 1914).

Freud, S. (2010a). Prefácio a O método Psicanalítico, de Oskar Pfister. In: S. Freud. Obras completas volume 10. Observaçôes psicanaliticas sobre um caso de paranoia relatado em autobiografia ("o caso Schreber"), artigos sobre técnica e outros textos (1911-1913). (pp. 340-343). São Paulo: Companhia das Letras. (Trabalho originalmente publicado em 1913).

Freud, S. (2010b). A dinâmica da transferência. In: S. Freud. Obras completas volume 10. Observaçôes psicanaliticas sobre um caso de paranoia relatado em autobiografia ("o caso Schreber"), artigos sobre técnica e outros textos (1911-1913). (pp. 133-146). São Paulo: Companhia das Letras. (Trabalho originalmente publicado em 1912).

Freud, S. (2010c). Observações sobre o amor de transferência. In: S. Freud. Obras completas volume 10. Observaçôes psicanaliticas sobre um caso de paranoia relatado em autobiografia ("o caso Schreber"), artigos sobre técnica e outros textos (1911-1913). (pp. 210-228). São Paulo: Companhia das Letras. (Trabalho originalmente publicado em 1915).

Freud, S. (2011). Prólogo à juventude Abandonada de August Aichhorn. In: S. Freud. Obras completas volume 16. O Eu e o Id, "autobiografia" e outros textos (1923 - 1925). (pp. 347-350). São Paulo: Companhia das Letras. (Trabalho originalmente publicado em 1925). 
Freud, S. (2014). A questão da análise leiga: diálogo com um interlocutor imparcial. In: S. Freud. Obras completas volume 17. Inibição, sintoma e anguistia, o futuro de uma ilusão e outros textos (1926-1929). (pp. 99-186). São Paulo: Companhia das Letras. (Trabalho originalmente publicado em 1926).

Freud, S. (2018). Análise terminável e interminável. In: S. Freud. Obras completas volume 19. Moisés e o monoteísmo, Compêndio de Psicanálise e outros textos (1937 - 1939). (pp. 274-326). São Paulo: Companhia das Letras. (Trabalho originalmente publicado em 1937).

Imbert, F. (2001). A questão da ética no campo educativo. Petrópolis: Vozes.

Jorge, M. A. C. (2006). Lacan e a formação do psicanalista. Rio de Janeiro: Contra Capa.

Kupfer, M. C. M. (1991). Freud e a educação: o mestre do impossível. São Paulo: Scipione.

Lacan, J. (1992). O seminário, Livro 17: o avesso da psicanálise, 1969-1970. Rio de Janeiro: Jorge Zahar Editor.

Lacan, J. (1997). O saber do psicanalista. Seminário 1971-1972. Centro de estudos freudianos do Recife.

Lacan, J. (1998). O tempo lógico e a asserção da certeza antecipada. In: J. Lacan. Escritos. (pp. 197-213). Rio de Janeiro: Jorge Zahar Editor. (Trabalho originalmente publicado em 1945).

Lacan, J. (2003a). Proposição de 9 de outubro de 1967 sobre o psicanalista de escola. In: J. Lacan. Outros escritos. (pp. 249-264). Rio de Janeiro: Jorge Zahar Editor. (Trabalho originalmente publicado em 1968).

Lacan, J. (2003b). Televisão. In: J. Lacan. Outros escritos. (pp. 508-543). Rio de Janeiro: Jorge Zahar Editor. (Trabalho originalmente publicado em 1974).

Lacan, J. (2003c). Introdução à edição alemã de um primeiro volume dos Escritos. In: J. Lacan. Outros escritos. (pp. 550-556). Rio de Janeiro: Jorge Zahar Editor. (Trabalho originalmente publicado em 1973).

Lajonquiére, L. (1999). Infância e ilusão (psico)pedagógica: escritos de psicanálise e educação. São Paulo: Vozes.

Lima, G. K. de, \& Langhi, R. (2021). Observando o invisível: a relação transferencial a partir dos discursos entre crianças e professoras monitoras em um observatório astronômico. Ensaio Pesquisa em Educação em Ciências, 23. https://doi. org/10.1590/1983-21172021230115.

Millot, C. (1987). Freud antipedagogo. São Paulo: Jorge Zahar Editor.

Minerbo, M. (2012). Transferência e contratransferência. São Paulo: Casa do Psicólogo

Mrech, L. M. (1999). Psicanálise e educação: novos operadores de leitura. São Paulo: Thomson Learning.

Pedroza, R. L. S. (2010). Psicanálise e Educação: análise das práticas pedagógicas e formação do professor. Psicologia da Educação. 30, pp. 81-96.

Penna, L. M. D. M. (2003). Psicanálise e universidade: há transmissão sem clínica? Belo Horizonte: Autêntica.

Pereira, M. R. (2005). Subversão docente: ou para além da "realidade do aluno". In: L. Mrech. M. O impacto da psicanálise na educação. (pp. 93-116). São Paulo: Avercamp.

Pommier, G. (1990). O desenlace de uma análise. Rio de Janeiro: Jorge Zahar Editor.

Quinet, A. (2009). As 4+1 condições da análise. Rio de Janeiro: Jorge Zahar Editor.

Silva, G. S. F. da. \& Villani, A. (2012). A dinâmica de um grupo de alunas nas aulas de Física, a sua relação com o saber e as intervenções do professor. Investigações em Ensino de Ciências, 17(1), 183-208.

Valadares, J. M. \& Villani, A. (2004). Crise, mudança e intermediário: o papel do professor de Ciências na constituição das relações intersubjetivas em um grupo de professores. Ensaio. Pesquisa em Educação em Ciências, 6(1), 09-23.

Villani, A. (1999). O professor de Ciências é como um analista? Ensaio. Pesquisa em Educação em Ciências, 1(1), 06-24. 
Villani, A. \& Barolli, E. (2000). Interpretando a Aprendizagem nas Salas de Aula de Ciências. In XXIII Reunião anual da ANPED. Atas da XXIII ANPED - CD-Room GT-04, (pp. 1-20). Disponível em: < https://anped.org.br/sites/ default/files/5_interpretando_a_aprendizagem_nas_salas_de_aula_de_ciencias.pdf $>$. Acesso em: 16 jul. 2021.

Villani, A. \& Barolli, E. (2006). Os discursos do professor e o ensino de Ciências. Pro-Posições, 17(1), 155-175.

Villani, A., Barolli, E. \& Cabral, T. C. B., Fagundes, M. B., Yamazaki, S. C. (1997) Filosofia da Ciência, História da Ciência e Psicanálise: analogias para o ensino de Ciências. Cad. Cat. Ens. Fis., 14(1), 37-55.

Villani, A., Barolli, E., Arruda, S. M., Franzoni, M., Valadares, J. M., Gurudi, V. \& Ferreira, D. B. (2011). Contribuições da Psicanálise para uma metodologia de pesquisa em educação em ciências. In F. M. T. Santos \& I. Grega, (org.) $A$ pesquisa em Ensino de Ciências no Brasil e suas metodologias. (pp. 323-390). Unijuí: Ed. Unijuí.

Villani, A., Barros, M. A., \& Arruda, S. M. (2011). Impasses na sala de aula de ciências: a psicanálise pode auxiliar?. Revista Brasileira De Pesquisa Em Educą̧ão Em Ciências, 4(1), 31-44. Disponível em: https://periodicos.ufmg.br/ index.php/rbpec/article/view/4094. Acesso em: 16 jul. 2021.

Villani, A., Santana, D. A. \& Arruda, S. M. (2003). Perfil subjetivo: estudos de caso. Caderno Catarinense de Ensino de Fisica, 20(3), 336-371.

Villani, A. \& Cabral, T. C. B. (1997). Mudança conceitual, subjetividade e psicanálise. Investigações em Ensino de Ciências, 2(1), 43-61.

Villani, A. \& Carvalho, L. O. de. (2005). Discurso do professor e subjetividade na aprendizagem de Física. Investigaçôes em Ensino de Ciências, 10(3), 363-386.

Villani, A. \& Franzoni, M. (2000). A competência dialógica e a formação de um grupo 'docente'. Investigações em Ensino de Ciências, 5(3), 191-211.

Villani, A. \& Santana, D. A. (2004). Analisando as interações dos participantes numa disciplina de física. Ciência छ Educação, 10(2), 197-217.

Villani, A., Dias, V. S. \& Valadares, J. M. (2010). The Development of Science Education Research in Brazil and Contributions from the History and Philosophy of Science. International Journal of Science Education, 32(7), 907-937.

Voltolini, R. (2011). Educação e psicanálise. São Paulo: Jorge Zahar Editor.

\section{NOTAS}

1 Artigo produzido a partir de pareceres emitidos ao artigo: Lima, G. K. de, \& Langhi, R. (2021). Observando o invisível: a relação transferencial a partir dos discursos entre crianças e professoras monitoras em um observatório astronômico. Ensaio Pesquisa em Educação em Ciências, 23.

2 Sobre o tempo lógico em Jacques Lacan conferir: “O tempo lógico e a asserção da certeza antecipada” (Lacan, 1998); "As 4+1 condiçôes da análise" (Quinet, 2009).

3 Sobre transferência conferir: "Transferência e contratransferência" (Minerbo, 2012); "Transferência e introjeção" (Ferenczi, 2011a); “A dinâmica da transferência” (Freud, 2010b); “Observações sobre o amor de transferência” (Freud, 2010c).

4 Sobre a formação do analista conferir: "A questão da análise leiga: diálogo com um interlocutor imparcial" (Freud, 2014); "Lacan e a formação do psicanalista" (Jorge, 2006); "Proposição de 9 de outubro de 1967 sobre o psicanalista de escola” (Lacan, 2003a); “As 4+1 condições da análise” (Quinet, 2009).

5 Sobre o término da análise conferir: "O desenlace da análise” (Pommier, 1990); "Como terminam as análises: textos reunidos” (Associação Mundial de Psicanálise, 1995); “O problema do fim da análise” (Ferenczi, 2011b); "Análise terminável e interminável” (Freud, 2018). 


\section{Wilson Elmer Nascimento}

Doutor em Ensino de Ciências e Matemática pela Universidade Estadual de Campinas (UNICAMP) e psicanalista em formação pelo Percurso Livre em Psicanálise (PLP/Natal).

Professor do Centro de Educação da Universidade Federal do Rio Grande do Norte (UFRN). Natal, RN, Brasil.

E-mail: wilson-elmer@hotmail.com

\section{Alberto Villani}

Doutor em Física pela Universidade Estadual Paulista Júlio de Mesquita Filho (UNESP).

Professor Sênior do Instituto de Física da Universidade de São Paulo (USP). São Paulo, SP, Brasil.

E-mail: avillani@if.usp.br

Contato:

Wilson Elmer Nascimento

Departamento de Práticas Educacionais e Currículo

Centro de Educação - Universidade Federal do Rio Grande do Norte - UFRN

Campus Universitário UFRN, Lagoa Nova, Natal - RN | Brasil

CEP 59.072-970

Editor responsável:

Glauco dos Santos Ferreira da Silva

\section{ERRATA}

DOI | http://dx.doi.org/10.1590/1983-21172021230126er

Na página 1, onde se lê, no cabeçalho, ARTIGO.

Leia-se:

PERSPECTIVAS. 